\title{
Prompting Challenges
}

\author{
Forthcoming in Analysis \\ John Turri \\ Huron University College \\ john.turri@gmail.com
}

I consider a serious objection to the knowledge account of assertion and develop a response. In the process I introduce important new data on prompting assertion, which all theorists working in the area should take note of.

\section{Challenging Objections}

The knowledge account of assertion (KA) says you may assert Q only if you know Q. Many objections have been raised against KA (e.g. Weiner 2005, Douven 2006, Lackey 2007, Hill and Schechter 2007, Levin 2008, Kvanvig 2009, and Brown forthcoming). Here I'll focus on one objection in particular, and offer a response.

A major part of the case for KA is an explanatory argument from conversational patterns (Unger 1975: 260 ff.; Williamson: Chapter 11; Reynolds 2002; DeRose 2002). Our discussion takes one of these patterns as its point of departure: appropriate chal- 
lenges to assertion. ${ }^{1}$ When I assert Q, even if Q has nothing to do with me or what I know, asking me 'How do you know?' is normally appropriate (Unger 1975: 263 - 4, acknowledging Michael Slote for the insight; Williamson 2000). KA easily explains this. By asserting Q, I represent myself as having authority to do so, which amounts to knowing Q. This renders your question appropriate.

Echoing a worry expressed by Timothy Williamson (2000: 254), Jonathan Kvanvig (2009) rejects this as good evidence for KA. Says Kvanvig,

This line of argument may prove too much. It is also appropriate to ask, "Are you certain?" [and] "Are you absolutely sure?”. If the conversational propriety of various questions is an argument in favor of the knowledge account, the propriety of these questions is an argument in favor of a stronger account: that one must be absolutely certain in order for a claim to be assertible. Moreover, it is also appropriate to ask of an assertor, "Do you have any good reason to think that?" . . . . If conversational propriety of questions were our only data, we'd have no good reason to single out the knowledge account as opposed to some weaker or stronger account.

We have two objections here, deriving from natural ways to chal-

Weiner cites this as one of three primary data supporting KA. I think that underestimates things, but it still gives you an idea of how serious a blow it would be to undermine this datum. 
lenge assertions. Call a stronger challenge one that suggests that something more than knowledge is required to authorize assertion. Such challenges ask whether the speaker is 'certain' or 'absolutely certain' or 'sure' or 'absolutely sure' about the proposition asserted. Call a weaker challenge one that suggests that something less than knowledge can authorize assertion. Such challenges might (i) ask whether the speaker 'has good reasons for' or 'is justified in believing' or 'has any evidence for' the proposition asserted, or (ii) ask whether the speaker 'believes' or 'really believes' or insists that the speaker 'doesn't even believe' the proposition asserted, or (iii) ask whether the asserted proposition is 'really true' or even rejects it as 'false'.

Let's encapsulate Kvanvig's twin objections like so:

(O1) Weaker challenges suggest that KA is too strong. ${ }^{2}$

(O2) Stronger challenges suggest that KA is too weak. ${ }^{3}$

I'll briefly respond to $\mathrm{O} 1$ before turning to $\mathrm{O} 2$, which is my primary focus here. To question whether someone satisfies a necessary condition on knowledge is ipso facto to question whether she knows. Reasonable true belief is necessary for knowledge. So to question whether it is reasonable for her to believe $Q$ is to question whether she knows Q. Likewise, to question whether someone believes $\mathrm{Q}$ is to question whether she knows $\mathrm{Q}$. Likewise again, to question whether $\mathrm{Q}$ is true is to question whether she knows $\mathrm{Q}$. Thus if KA is true, then we would expect any of these weaker chal-

2 Jennifer Lackey (2007: 610) raises a similar worry.

3 Jason Stanley (2008) raises a similar worry. 
lenges to be appropriate. We would expect them to be appropriate because they question whether you satisfy a necessary condition on knowledge, and thereby count as questioning your authority to assert.

To see how natural this type of response is, consider how Kvanvig might respond to a similar objection to his favored account of assertion, the reasonable belief account (RBA), which says you may assert $\mathrm{Q}$ only if you have a reasonable belief that $\mathrm{Q}$. All these appropriate challenges are weaker relative to RBA: 'You don't believe that', 'Do you really believe that?', 'You have no evidence for that!', and 'What reason do you have to believe that?'. Can RBA explain their propriety? Yes. Believing $Q$ is a necessary condition on having a reasonable belief that $\mathrm{Q}$, so to question whether someone believes is to question whether he has a reasonable belief. Having evidence or (good) reasons to believe $\mathrm{Q}$ is a necessary condition on having a reasonable belief that $\mathrm{Q}$, so to question whether someone has evidence or reasons is to question whether he has a reasonable belief. This strategy for handling weaker challenges is versatile.

\section{Reassuring Prompts}

If knowledge authorizes assertion, then why is it appropriate to challenge an assertion by asking 'Are you certain?' or 'How can you be certain?'? (The question rightly presupposes that knowledge doesn't require certainty.)

Williamson (2000: 254) considered a similar objection and ori- 
ginally suggested that, while people are generally not "happy" to let the standards for knowledge and certainty diverge, we can nevertheless 'to some extent' achieve separation between them, 'and then assertability goes with knowledge, not with the highest possible standards of certainty.' Williamson continues:

For example, one may have warrant to assert 'A and by Descartes's standards I cannot be absolutely certain that A', where the reference to Descartes holds those standards apart from the present context. Again, it would often be inappropriate to respond to the assertion 'A' by asking 'How can you be so certain that A?'. The word 'so' flags the invocation of unusually high standards of certainty. By ordinary standards you may have had warrant to assert that A even if you could not be so certain that A. (2000: 254)

This is unlikely to satisfy. The challenges 'Are you certain?' and 'Are you sure?' invoke ordinary standards of certainty and assuredness, not the highest possible standards. They don't invoke Cartesian standards. It may be true that 'How can you be so certain?' is uncommon and typically inappropriate. But we're still left to address the propriety of 'How can you be certain?' and its ilk (absent the intensifier 'so'). Williamson's response doesn't speak to this problem. ${ }^{4}$

4 His overall view would enable a different response, but for that to work, we'd need to accept his view of the relation between evidence, evidential probability and knowledge. It would be satisfying to have a more direct response that presupposed less theoretical baggage. 
I suggest a three-part response instead. First, we should demonstrate that the propriety of stronger challenges is consistent with KA. Second, we should show how KA accounts for their propriety. Third, we should place these stronger challenges in a broader context, where we may assess their true significance.

First, is the propriety of stronger challenges consistent with KA? Consider an analogy. We're attending a wedding ceremony. We reach the point where the official says, 'I now pronounce you husband and wife'. By saying this, the official represents herself as having the authority to marry the couple. It would be appropriate to ask her, 'Are you authorized to marry couples?'. It would also be appropriate to ask, 'Are you sure you're authorized to do that?', or 'Are you certain you're allowed to do that?'. (It might be unwise or impolite or inconsiderate to question her this way, but those are separate issues.) Authorization to wed couples is one thing; it requires being licensed by the state. Being sure that you're authorized to wed couples is something else entirely; the state issues no license for that. The propriety of the stronger challenge here does not tend to show that being sure you're authorized is what authorizes you. Being licensed is what authorizes you.

Second, how can KA explain the propriety of the stronger challenges? KA at least has a plausible story to tell here. On the one hand, suppose that, according to ordinary standards, to appropriately be certain of $Q$ requires (roughly) knowing that you know that Q. So to ask a speaker whether he's 'certain' is basically to ask him whether he knows that he knows (compare Rysiew 2007: 636 - 7, 
657-8 n. 13). On the other hand, by asserting, he represent himself as knowing. So asking him whether he's certain is proper because it amounts to asking him whether he knows that he is accurately representing himself. ${ }^{5}$ It remains to be seen whether KA's weaker competitors have anything as plausible to offer. ${ }^{6}$

Notice one thing that we needn't explain. We needn't explain the propriety of 'You aren't certain of that!' or 'You're not absolutely sure of that!', because intuitively those challenges are out of line. They're too harsh, too demanding. It might sound okay to ask someone whether they're certain of what they say, but it doesn't sound okay to flat-out accuse them of not being certain or absolutely sure. Contrast that with the propriety of 'You don't know that', which is aggressive but not improper. We could summarize this point by saying that certainty does not figure in as full a range of appropriate challenges as knowledge does.

Third, what broader perspective will safely put the threat of stronger challenges to rest once and for all? A perspective that also

5 Of course, to make this work, KA's proponents need not insist on a more general knowledge account of representation (i.e. you may represent $Q$ in any way whatsoever only if you know $Q$ ). The account need only explain why it would seem relevant and appropriate to issue such challenges. I actually find challenges involving certainty and assuredness a bit heavy-handed, so I would prefer that my overall view not entail that they are definitely appropriate. But since many others seem to intuit otherwise, I do at least want an account that can explain the appearance of the propriety, or at least why they're not positively improper. (In connection with this, recall that 'You're not certain of that!' and 'You're not absolutely sure of that!' are inappropriate challenges.)

6 The certainty account of assertion has an obvious explanation. See Stanley 2008. 
takes note of appropriate prompts to assertion. This reveals knowledge to be more closely connected to assertion than is certainty.

Suppose I'm wondering what time the meeting starts. You're the committee chairperson, so I ask you. I could ask you any number of ways. But here are two very common and perfectly appropriate ways to prompt you: 'What time does the meeting start?' and 'Do you know what time the meeting starts?'. These two prompts are practically interchangeable. Competent speakers respond to them identically. When we ask 'Do you know what time the meeting starts?', if they know, they respond by saying 'Four o'clock', not 'Yes, I do know'. Responding with 'Yes, I do know' could be interpreted as either playful or humorous, but is otherwise interpreted as uncooperative. Oversimplifying a bit, we can put the point this way: 'Do you know whether Q?' is transparent to whether Q.7

Call a stronger prompt one that attempts to elicit assertion by literally asking for something more than knowledge. Such prompts ask the speaker whether she is 'certain' or 'absolutely certain' or 'sure' or 'absolutely sure' about something. The crucial point: stronger prompts are inappropriate. It is unnatural, and indeed somewhat alienating, for me to prompt you with 'Are you certain about what time the meeting starts?' or 'Are you absolutely sure (about) what time the meeting starts?'. Those are too demanding. Questions about certainty and assuredness typically become appropriate only after an assertion has been made. True, we could

7 An exercise for the reader: see how many times you need to repeat (and alter natural patterns of emphasis in) 'Do you know whether $Q$ ?' to get a direct response to your literal question. 
make them sound natural and non-alienating by prefacing them: 'I've been late to the last four meetings and I simply cannot afford to be late again - can you tell me with absolute certainty what time today's meeting starts?'. But that's not the normal case. ${ }^{8}$

That completes my defense of KA against O2. But before concluding, it's worth briefly noting another point. Call a weaker prompt one that attempts to elicit assertion by literally asking for something less than knowledge. Such prompts might ask merely what the speaker thinks about some question, or whether the speaker has any evidence about how to answer some question. Some weaker prompts are appropriate. Instead of saying 'What time does the meeting start?', I might say 'What time do you think the meeting starts?', or 'Do you have any indication (evidence) about what time the meeting starts?', though the latter is less natural and more likely to result in an assertion that doesn't directly answer the question 'What time does the meeting start?'. KA's competitors include RBA (mentioned above) and the reasonable to believe account, which says (roughly) that you may assert Q only if it is reasonable for you to believe Q (see Douven 2006 and Lackey 2007). If either view were correct, we would expect certain corresponding weaker prompts to sound natural, including 'Do you have a reasonable belief about what time the meeting starts?', and 'What

8 We might also wonder whether, in such a context, responding with 'Four o'clock' would amount to merely asserting that the meeting starts at four o'clock, as opposed to performing a more emphatic speech act, such as guaranteeing that the meeting starts at four. But here I set that issue aside. For more on this, see Turri 2010. 
time is it reasonable for you to think the meeting starts?'. But those are very unnatural.

The data on appropriate challenges is only half the story. Knowledge features in appropriate challenges and appropriate prompts to assertion. Certainty features in appropriate challenges but not appropriate prompts. And certainty does not figure in as full a range of appropriate challenges as knowledge does. This demonstrates that knowledge is more intimately related to assertion than is certainty. This suggests that if either the knowledge account or the certainty account is correct, then certainly the knowledge account is. ${ }^{9}$

9 For help with this paper, I thank Matt Benton, Jon Kvanvig, Aidan McGlynn, and Angelo Turri. 


\section{References}

Brown, Jessica. Forthcoming. "Knowledge and Assertion." Philosophy and Phenomenological Research.

DeRose, Keith. 2002. "Assertion, Knowledge and Context." Philosophical Review 111:2, 167- 203.

Douven, Igor. 2006. "Assertion, Knowledge, and Rational Credibility." Philosophical Review 115:4, 449 - 85.

Hill, Christopher S. and Joshua Schechter. 2007. "Hawthorne's Lottery Puzzle and the Nature of Belief." Philosophical Issues 17, $102-122$.

Kvanvig, Jonathan L. 2009. "Assertion, Knowledge, and Lotteries." In Williamson on Knowledge, ed. Pritchard and Greenough. Oxford: Oxford University Press. URL= <http://www3.baylor.edu/ Jonathan_Kvanvig/pdf/knowledge,\%20assertion,\%20and\%2olotteries.pdf>, accessed 18 July 2008.

Lackey, Jennifer. 2007. "Norms of Assertion." Noûs 41:4, 594 626.

Levin, Janet. 2008. "Assertion, Practical Reason, and Pragmatic Theories of Knowledge." Philosophy and Phenomenological Research 76:2, $359-84$.

Reynolds, Steven L. 2002. "Testimony, Knowledge, and Epistemic Goals." Philosophical Studies 110:2, 139 - 161.

Rysiew, Patrick. 2007. "Speaking of Knowledge.” Noûs 41:4, 627 62.

Stanley, Jason. "Knowledge and Certainty." Philosophical Issues 18, $33-55$.

Turri, John. 2010. "Epistemic Invariantism and Speech Act Contextualism." Forthcoming in Philosophical Review 119:1.

Unger, Peter. 1975. Ignorance: A Case for Skepticism. Oxford: Oxford University Press.

Weiner, Matthew. 2005. "Must We Know What We Say?" Philosophical Review 114:2, 227 - 251. 
Williamson, Timothy. 2000. Knowledge and Its Limits. Oxford: Oxford University Press. 